\title{
I-F STARTING METHOD FOR SMOOTH AND FAST TRANSITION TO SENSORLESS FIELD ORIENTED CONTROL OF BLDC MOTORS
}

\author{
Cassio Luciano Baratieri, Humberto Pinheiro \\ Federal University of Santa Maria \\ Santa Maria - RS - Brazil \\ e-mail: cassio.baratieri@gmail.com, humberto.ctlab.ufsm.br@gmail.com
}

\begin{abstract}
This paper proposes an I- $f$ starting method for smooth and fast transition from open-loop frequency control to sensorless field oriented control of BLDC motors. The method is divided in three stages: (i) initially the rotor is aligned with a desired angular position; (ii) then, the stator currents are controlled in an arbitrary reference frame to impose the angular frequency of the rotating magnetic field with a suitable profile; (iii) finally, a smooth transition between the arbitrary and the rotor reference frames is accomplished by recalculating the current controller states and references. The proposed method preserves the electromagnetic torque magnitude during the transition avoiding undesired transients. In addition, a procedure based on mechanical model is described to determine a suitable ramp profile. Moreover, the estimated rotor position that is required for FOC as well as for the proposed method is computed by using the estimated back-EMFs from a Luenberger observer. The good performance and robustness under no-load and full load conditions of the proposed starting method are demonstrated by simulation and experimental results.
\end{abstract}

Keywords - Brushless DC Motor, I- $f$ Starting, PM Motor Drives, Sensorless Vector Control, Variable Speed Drives.

\section{NOMENCLATURE}

$\begin{array}{ll}i & \text { Stator current. } \\ v & \text { Stator voltage. } \\ e & \text { Phase back-EMF. } \\ R_{s} & \text { Stator resistance. } \\ L_{s} & \text { Stator inductance. } \\ \theta_{e}, \theta_{r} & \text { Electrical and mechanical rotor position. } \\ T_{e}, T_{l} & \text { Electromagnetic and load torque. } \\ \omega_{r} & \text { Rotor speed. } \\ P & \text { Number of poles. } \\ \lambda_{\text {pm }} & \text { Permanent magnet flux linkage. } \\ J & \text { Moment of inertia. } \\ B & \text { Friction coefficient. } \\ K_{\text {obs }} & \text { Observer gain. } \\ K_{\text {com }} & \text { Phase lag compensator gain. } \\ \theta_{\text {com }} & \text { Phase lag compensator angle. } \\ K_{\omega 1}, K_{\omega 2} & \text { Speed controller gains. } \\ K_{C 1}, K_{C 2} & \text { Current controller gains. } \\ u_{c} & \text { Control actions. } \\ e_{c} & \text { Error signals. } \\ \omega_{\text {start }} & \text { Speed reference signal during the starting. } \\ \theta_{\text {start }} & \text { Orientation angle during the starting. }\end{array}$

Artigo submetido para avaliação em 03/02/2014. Primeira revisão em 05/05/2014, segunda revisão em 07/06/2014. Aceito para publicação em 07/08/2014 por recomendação do Editor Henrique A. C. Braga.
$\theta^{*}$
Angular difference between the arbitrary and the rotor reference frame.
$\theta_{t}^{*}, \theta_{r p}^{*}$
Angular difference between the arbitrary and the rotor reference frame at the transition instant and at the end of the ramp.
$\omega_{f} \quad$ Angular speed at the end of the ramp.
$T_{r} \quad$ Ramp-up time interval.
$v_{f} \quad$ Feedforward actions.
$T_{s} \quad$ Sampling time period.

Superscripts

Estimated values.

Estimation errors.

* Variable represented in the arbitrary reference frame.

\begin{tabular}{|c|c|}
\hline$\alpha, \beta$ & $\begin{array}{l}\text { Variable represented in the stationary reference } \\
\text { frame. }\end{array}$ \\
\hline$d, q$ & $\begin{array}{l}\text { Variable represented in the rotor reference } \\
\text { frame. }\end{array}$ \\
\hline ref & Reference value. \\
\hline $\max$ & Maximum value. \\
\hline ini & Initial value. \\
\hline
\end{tabular}

\section{INTRODUCTION}

The increase in electricity consumption has been a global concern in the last few decades. Governments, industries and academics are searching for sustainable solutions for this challenge. The improvement in electrical motor efficiency can contribute to reduce electricity consumption, since electrical motors, especially induction motors, account for a large part of the global electricity demand [1]. Permanent magnet (PM) brushless motors are one alternative to improve the energy efficiency of motor drive applications. These motors can provide high-power density, high efficiency and torque to inertia ratio when compared with DC and induction motors [2].

PM motors can be classified in two categories according to its back electromotive force (back-EMF). The first one are sinusoidal back-EMF motors which are often called PM synchronous motor (PMSM) or AC brushless motor. The second one are trapezoidal back-EMF motors which are denominated DC brushless (BLDC) motor. The former tend to be more expensive than the latter due to performance requirements and constraints on motor design. As a result, BLDC motors have been an attractive choice for the mass-production industry that manufactures pumps, fans and compressors.

PM brushless motors require synchronization to be appropriately driven. Usually, the rotor angle is used as a reference for the synchronization. This angle can be measured by me- 
chanical sensors or estimated by sensorless methods [3]-[6]. The choice among the methods depends on application. For instance, in mass-production industry, production costs, mechanical robustness, and control performance impose requirements and constraints that must be taken into account. In cases where production cost is very important and lowspeed operation is not required, sensorless control methods based on back-EMF are preferred [7]. However, these methods fail with the motor at standstill. Consequently, a starting method is required to accelerate the motor to a speed that allows the back-EMF to be accurately estimated.

Several methods for PM motor starting can be found in the literature. Methods based on $v-f$ control are presented in [8]-[11]. Although these methods are open-loop control strategies with easy implementation, they are sensitive to load/motor parameters. Starting methods for BLDC motors under scalar control are proposed in [11] and [12]. These methods synchronize the commutation instants of the inverter with the disturbance that is caused by the back-EMF on the current or on the current loop control action, but they are unsuitable for vector control. On the other hand, [13] and [14] show starting methods based on high-frequency signal injection. Even though these approaches may result in a highperformance starting, they depend on the motor anisotropy and on appropriate measurement sensors. Finally, I- $f$ starting methods with transition to field oriented control (FOC) are proposed in [7], [15], [16]. In these approaches, the magnitude of the stator currents is controlled with a constant reference and it is imposed a frequency profile similar to $v-f$ control.

Usually I $f$ starting methods have good performance and robustness for different loads, as demonstrated by [7], [15], [16]. In addition, I- $f$ control prevents the PM demagnetization due to high stator currents when it is compared with $v-f$ control methods. However, a concern about these methods is the transition between open-loop and sensorless control. A smooth transition is desired in order to avoid high transient currents, abruptly change in rotor speed and electromagnetic torque, and operation failures. In [15], a first-order lag compensator is employed to ensure a transition to FOC. The compensator allows a smooth commutation between the angular orientations. However, the convergence depends on the compensator design that can vary among motor drives. Similar limitation is found in [16] where a frequency-dependent gain is used to provide a smooth transition. On the other hand, [7] proposes the reduction of quadrature reference current in ramp to minimize the orientation error during the transition. Even though, all methods may provide a good transition, all of them require an additional procedure and a careful design.

Supposing that the rotor position is correctly estimated during the motor starting, the stator currents and voltages can be represented in the rotor reference frame. Therefore, the states and the references of the current controllers can be also computed in both reference frames: the arbitrary reference frame that is defined by I- $f$ control and the estimated rotor reference frame. In other words, the current controllers can be easily recalculated taking into account the orientation error of FOC at the transition instant. This process allows a proper

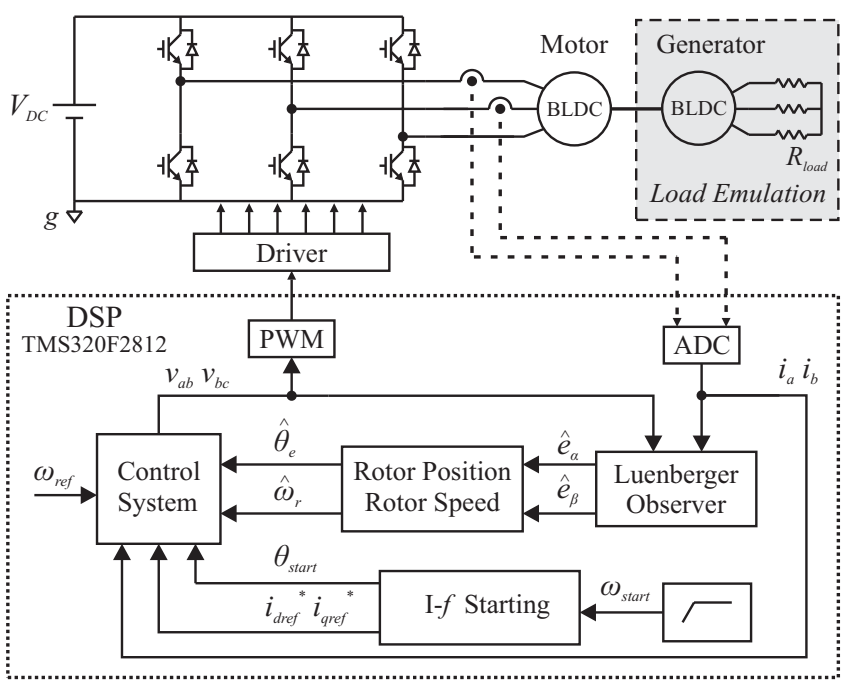

Fig. 1. Overview of the proposed starting method.

change between the reference frames avoiding undesired transients. In this paper, an I- $f$ starting method for smooth and fast transition to sensorless FOC based on the mentioned assumption is proposed. The method is divided in three stages and it is applied to a BLDC motor. In the first stage, the rotor is aligned with a desired angular position energizing two out of three windings. In the second stage, stator currents are controlled in an arbitrary reference frame accelerating the motor to a designed speed. In addition, a procedure based on the mechanical dynamics is proposed to design a suitable ramp slope that imposes the angular frequency of the rotating magnetic field. The last stage is the transition between the starting and FOC. At this instant, the states and references of $d-q$ current controllers are recalculated according the previous hypothesis. When comparing with the previously mentioned methods, the proposed method reduces the starting design complexity and minimizes the time interval for transition to sensorless FOC. In addition, this methodology can be easily adapted for another controllers. Moreover, the design procedures that determine the ramp slope provide degrees of freedom to improve the starting ensuring the robustness and smoothness for different load conditions. Furthermore, this method keeps the electromagnetic torque approximately constant during the transition achieving an excellent transient response. The good performance is demonstrated by simulation and experimental results.

The rest of this paper is organized as follow. Section II presents an overview of the adopted sensorless FOC. Section III describes the proposed I- $f$ starting method. Simulation and experimental results are given and discussed in Section IV. Finally, conclusions are presented in Section V.

\section{SYSTEM DESCRIPTION}

In this section a dynamic model of the BLDC motor is derived aiming to design the current control loop. In addition, it is described the observer which has been used to obtain the angular position and speed that are required to sensorless FOC implementation as well as the proposed starting method.

Figure 1 shows an overview of the adopted platform to validate the proposed method. This platform consists of 
a surface mounted PM BLDC motor, a three phase PWM inverter, hall current sensors and a fixed-point DSP platform. The motor load is emulated by a BLDC generator that is connected to a resistive load, as shown in Figure 1. As a result, the motor load is proportional to the rotor speed.

The voltage equations of the BLDC motor in the stationary reference frame can be written as:

$$
\frac{d}{d t} \mathbf{i}_{\alpha \beta}=-\frac{R_{s}}{L_{s}} \mathbf{i}_{\alpha \beta}+\frac{\mathbf{v}_{\alpha \beta}}{L_{s}}-\frac{\mathbf{e}_{\alpha \beta}}{L_{s}}
$$

where $\mathbf{i}_{\alpha \beta}=\left[\begin{array}{ll}i_{\alpha} & i_{\beta}\end{array}\right]^{T}$ are the stator phase currents, $R_{s}$ is the stator resistance, $L_{s}$ is the stator inductance, $\mathbf{v}_{\alpha \beta}=\left[v_{\alpha} v_{\beta}\right]^{T}$ are the stator phase voltages and $\mathbf{e}_{\alpha \beta}=\left[e_{\alpha} e_{\beta}\right]^{T}$ are the phase back-EMFs.

By applying the Park's transformation in (1), the voltage equations can be represented in the rotor reference frame as:

$$
\begin{aligned}
& v_{d}=R_{s} i_{d}-\omega_{r} L_{q} i_{q}+L_{d} \frac{d}{d t} i_{d} \\
& v_{q}=R_{s} i_{q}+\omega_{r} L_{d} i_{d}+L_{q} \frac{d}{d t} i_{q}+\omega_{r} \lambda_{p m}
\end{aligned}
$$

where $i_{d}$ and $i_{q}$ are the direct and quadrature axes stator currents, $v_{d}$ and $v_{q}$ are the direct and quadrature axes stator voltages, $L_{d}$ and $L_{q}$ are the direct and quadrature axes inductances, $\lambda_{p m}$ is the permanent magnet flux linkage and $\omega_{r}$ is the rotor speed. The relationship among the adopted reference frames in this paper are presented in Figure 2.

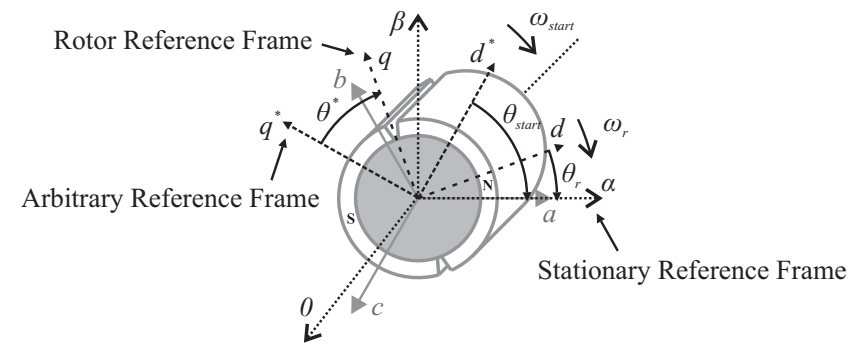

Fig. 2. Relationship among stationary, rotor and arbitrary reference frames.

The electromagnetic torque can be written as:

$$
T_{e}=\frac{P}{2}\left[\lambda_{p m}+\left(L_{d}-L_{q}\right) i_{d}\right] i_{q}
$$

where $P$ is the number of poles.

The equation of motion of the motor can be expressed by:

$$
\frac{d}{d t} \omega_{r}=\frac{T_{e}}{J}-\frac{B}{J} \omega_{r}-\frac{T_{l}}{J}
$$

where $T_{l}$ is the load torque, $J$ is the moment of inertia, $B$ is the friction coefficient. In addition, the rotor speed, electrical and mechanical rotor position are related by:

$$
\begin{gathered}
\frac{d}{d t} \theta_{r}=\omega_{r} \\
\theta_{e}=\frac{P}{2} \theta_{r}
\end{gathered}
$$

where $\theta_{e}$ and $\theta_{r}$ are the electrical and mechanical rotor position.

\section{A. Sensorless Control}

Figure 3 shows the block diagram of the proposed sensorless control. Although this motor has a nonsinusoidal back-EMF, the classical sinusoidal FOC is implemented here, since the main purpose is to demonstrate the effectiveness of the proposed starting method.

The estimated rotor position and speed are obtained from estimated back-EMFs that are determined by a Luenberger observer [5]. The back-EMF is considered as an unmodelled disturbance in the dynamic model of the observer, which can be written as:

$$
\frac{d}{d t} \hat{\mathbf{i}}_{\alpha \beta}=-\frac{R_{s}}{L_{s}} \hat{\mathbf{i}}_{\alpha \beta}+\frac{\mathbf{v}_{\alpha \beta}}{L_{s}}+K_{o b s} \frac{\left(\mathbf{i}_{\alpha \beta}-\hat{\mathbf{i}}_{\alpha \beta}\right)}{L_{s}}
$$

where $K_{\text {obs }}$ is observer gain and $\hat{\mathbf{i}}_{\alpha \beta}=\left[\begin{array}{ll}\hat{i}_{\alpha} & \hat{i}_{\beta}\end{array}\right]^{T}$ are the estimated stator currents.

In order to design the observer gain, the dynamic model of estimation error is first derived. This model is obtained by subtracting (8) from (1), which results:

$$
\frac{d}{d t} \tilde{\mathbf{i}}_{\alpha \beta}=\left(-\frac{R_{s}}{L_{s}}-\frac{K_{o b s}}{L_{s}}\right) \tilde{\mathbf{i}}_{\alpha \beta}+\frac{\mathbf{e}_{\alpha \beta}}{L_{s}}
$$

where $\tilde{\mathbf{i}}_{\alpha \beta}=\left[\begin{array}{ll}\tilde{i}_{\alpha} & \tilde{i}_{\beta}\end{array}\right]^{T}$ are estimation errors of the stator currents.

The observer gain can be defined by making the dynamics of the observer much faster than the disturbance, which in this case is the back-EMF. If the gain is not large enough, the estimation error will become significant impacting the orientation error. In this paper, $K_{o b s}$ has been selected to make $\left(R_{s}+K_{o b s}\right) / L_{s}$ larger than the highest frequency of the backEMF at the maximum rotor speed. It has been considered that the thirteenth harmonic component of the back-EMF is the highest component to be observed.

Now, by assuming that the derivative of the current estimation error is small, it is possible to obtain an estimate for the back-EMF, that can be written as:

$$
\hat{\mathbf{e}}_{\alpha \beta}=\left(R_{s}+K_{o b s}\right)\left(\mathbf{i}_{\alpha \beta}-\hat{\mathbf{i}}_{\alpha \beta}\right)
$$

where $\hat{\mathbf{e}}_{\alpha \beta}=\left[\begin{array}{ll}\hat{e}_{\alpha} & \hat{e}_{\beta}\end{array}\right]^{T}$ are estimated back-EMFs.

Figure 4 shows the block diagram that describes the adopted observer. Second order Butterworth low-pass filters (SLPF) are used to attenuate the high-frequency noise of back-EMF. In addition, a SLPF $\left(\mathrm{SLPF}_{3}\right)$ is used to filter the estimated speed. The cutoff frequency of the filters are given in the simulation and experimental results section.

The phase lags introduced by observer and $\mathrm{SLPF}_{1}$ in the estimated rotor position are compensated by adding a frequency-dependent term, which is expressed as:

$$
\hat{\theta}_{\text {com }}=K_{\text {com }} \hat{\omega}_{r}
$$

where $K_{c o m}$ is a gain for phase lag compensation. Note that the observer and $\mathrm{SLPF}_{1}$ phase response are assumed linear and proportional to electrical rotor speed in the operating region. This assumption can be considered because the cutoff frequency of them are higher than the highest fundamental frequency of back-EMF. Linear interpolation between the 


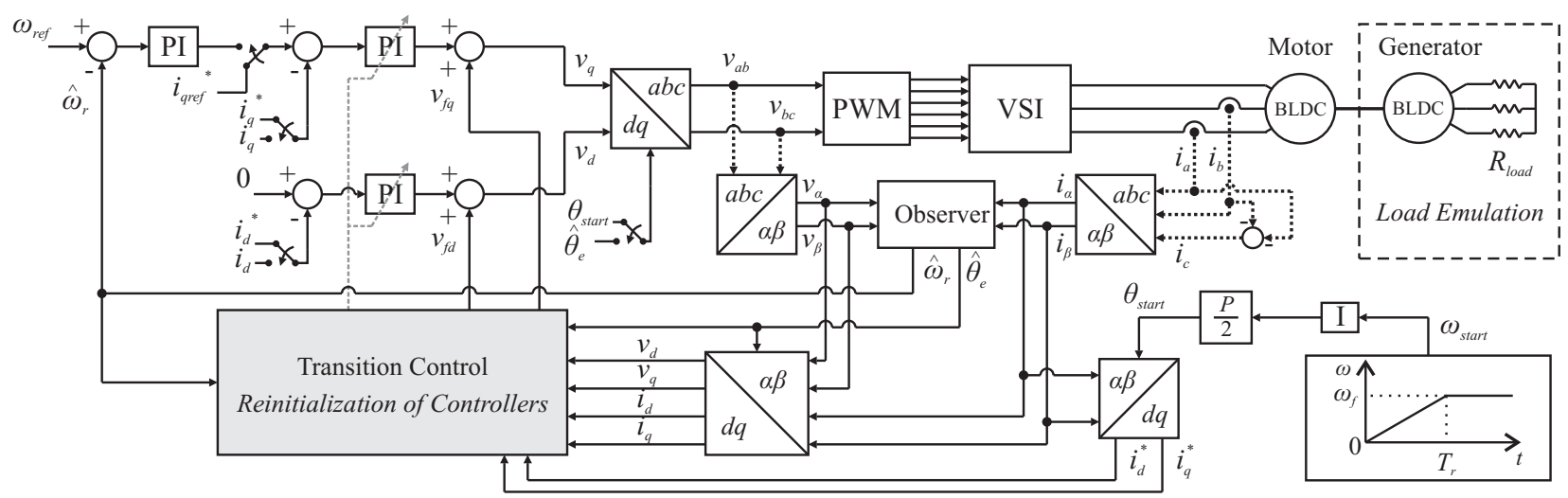

Fig. 3. Sensorless FOC system and proposed I- $f$ starting melhod.

lowest and highest phase delays in the operating region is used to determine $K_{\text {com }}$.

The estimated electrical rotor position is determined by

$$
\hat{\theta}_{e}=\arctan \left(\frac{-\hat{e}_{\alpha}}{\hat{e}_{\beta}}\right)+K_{c o m} \hat{\omega}_{r}
$$

On the other hand, by assuming that the rate of change of $K_{\text {com }} \hat{\omega}_{r}$ is small enough to be neglected, the estimated rotor speed can be given by:

$$
\hat{\omega}_{r}=\frac{2}{P} \frac{d}{d t} \hat{\theta}_{e}
$$

and it can be rewritten as

$$
\hat{\omega}_{r}=\frac{2}{P} \frac{\hat{e}_{\alpha} \frac{d}{d t} \hat{e}_{\beta}-\hat{e}_{\beta} \frac{d}{d t} \hat{e}_{\alpha}}{\hat{e}_{\alpha}{ }^{2}+\hat{e}_{\beta}{ }^{2}} .
$$

The differentiations in (14) are implemented by using first order high-pass filters (HPF) as shown in Figure 4.

Once the rotor speed is available, it is possible to control it. Here a PI speed controller has been adopted. The $z$-domain transfer function of the speed controller is:

$$
G_{P I}^{\omega}(z)=K_{\omega 1} \frac{z-K_{\omega 2}}{z+1}
$$

whereas the $d-q$ current controllers are expressed as:

$$
G_{P I}^{d q}(z)=K_{C 1} \frac{z-K_{C 2}}{z+1}
$$

where $K_{\omega 1}, K_{\omega 2}, K_{C 1}$ and $K_{C 2}$ are speed and current controller gains. These gains are tuned to ensure a desired open loop gain crossover frequency. In other words, $K_{\omega 2}$ and $K_{C 2}$ are determined in order to cancel the plant poles of the mechanical and the electrical systems. On the other hand, $K_{\omega 1}$ and $K_{C 1}$ are tuned to obtain a desired gain crossover frequency. Here, it is assumed that the system dynamics can be expressed as first-order transfer functions.

For the implementation, the transfer function (16) can be represented in a difference equation that is given by:

$$
\mathbf{u}_{c d q(k)}=K_{C 1}\left[\mathbf{e}_{c d q(k)}-K_{C 2} \mathbf{e}_{c d q(k-1)}\right]-\mathbf{u}_{c d q(k-1)}
$$

where $\mathbf{u}_{c d q}=\left[\begin{array}{ll}u_{c d} & u_{c q}\end{array}\right]^{T}$ are the control actions and $\mathbf{e}_{c d q}=$ $\left[e_{c d} e_{c q}\right]^{T}$ are the error signals.

\section{I-F STARTING METHOD}

As mentioned before the proposed method is divided in three stages: (i) the rotor is initially aligned; (ii) then, a reference frequency is imposed by controlling the stator currents in an arbitrary reference frame; (iii) finally, $d-q$ current controllers are recalculated to allow a fast change between references frames resulting in a smooth transition.

\section{A. Rotor Alignment}

Two approaches are often used to determine the initial rotor position. In the first one, high-frequency signals are used to identify the initial rotor angle at standstill [6], [14]. In the second one, the rotor is aligned with a desired angular position by energizing the stator windings. In this paper, two out of three windings are energized to provide the alignment. Here, it is considered that a reverse rotation is acceptable for a short time interval.

\section{B. I-f Control Method}

The I- $f$ control imposes a rotor speed by controlling the stator currents in an arbitrary reference frame. As BLDC motor is a synchronous machine, the rotor follows the angular frequency of the rotating magnetic field from standstill to a desired speed. A reference frequency with a suitable ramp slope defines the arbitrary reference frame as shown in Figure 3. During the I- $f$ control interval, the speed reference signal is given by:

$$
\omega_{\text {start }}= \begin{cases}\frac{\omega_{f}}{T_{r}} t & t<=T_{r} \\ \omega_{f} & t>T_{r}\end{cases}
$$

where $\omega_{f}$ is the desired rotor speed at the transition instant and $T_{r}$ is the time interval that with $\omega_{f}$ defines the ramp slope.

As a result, the orientation angle of the arbitrary reference frame is determined by:

$$
\theta_{\text {start }}=\int \omega_{\text {start }} d t+\theta_{\text {ini }}
$$

where $\theta_{i n i}$ is the initial angle that is established in the first stage.

Assuming the orientation reference shown in Figure 2, the electromagnetic torque from (4) can be expressed as:

$$
T_{e}=\frac{P}{2}\left[\lambda_{p m}+\left(L_{d}-L_{q}\right) i_{q}{ }^{*} \sin \left(\theta^{*}\right)\right] i_{q}{ }^{*} \cos \left(\theta^{*}\right)
$$




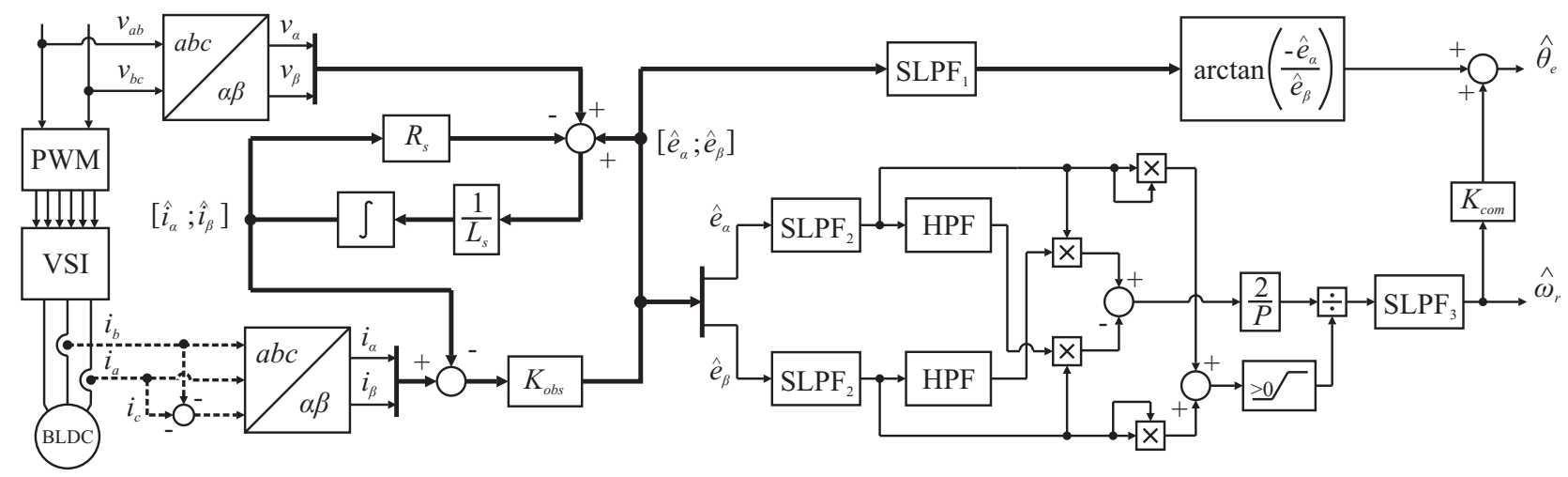

Fig. 4. Block diagram of the observer.

where $\theta^{*}$ is the angular difference between an arbitrary and the rotor reference frame, $i_{d}{ }^{*}$ and $i_{q}{ }^{*}$ are $d^{*}-q^{*}$ stator currents in the arbitrary reference frame. In addition, (20) has been derived considering $i_{d}{ }^{*}=0$.

Considering that the motor has surface mounted permanent magnets and the reluctance torque is negligible, the quadrature and direct axes inductances are assumed equal and constant. As a result,

$$
L_{d}=L_{q}=L_{s}
$$

and the electromagnetic torque from (20) can be simplified to

$$
T_{e}=\frac{P}{2} \lambda_{p m} i_{q}{ }^{*} \cos \left(\theta^{*}\right) .
$$

By substituting (22) into (5), the equation of motion during the starting can be written as:

$$
J \frac{d}{d t} \omega_{r}=\frac{P}{2} \lambda_{p m} i_{q}{ }^{*} \cos \left(\theta^{*}\right)-T_{l}-B \omega_{r} .
$$

From (18) and the adopted orientation shown in Figure 2, the rate of change of $\theta^{*}$ at ramp-up interval can be expressed by:

$$
\frac{d}{d t} \theta^{*}=\omega_{r}-\frac{\omega_{f}}{T_{r}} t
$$

Note that (23) and (24) are a nonhomogenous nonlinear second order differential equation, which is hard to solve analytically. In [7], an analysis of this equation is performed to design a suitable ramp slope, but the viscosity coefficient is neglected.

A qualitative analysis of (23), where it is assumed that $i_{q}{ }^{*}$ and $T_{l}$ are positive constants, can reveal two behaviors for the motor starting. In the first one, the motor operation is stable when $0 \leq \theta^{*}<90^{\circ}\left(\theta_{\text {start }}>\theta_{r}\right)$. This behavior has been reported by [7] as a self-stabilization capability. Let us consider that the load increases (perturbation), then the rotor speed and $\theta^{*}$ decrease causing an increase in the electromagnetic torque. Consequently, the motor will accelerate whenever $\theta^{*}$ remains non-negative. It can be concluded that the angular speed converges to a stable solution. In the second one, the operation is unstable leading to a failure in the motor start-up when $\theta^{*}<0\left(\theta_{\text {start }}<\theta_{r}\right)$. If the load torque increases, the rotor speed and the orientation error will reduce resulting in a smaller electromagnetic torque.
In order to ensure a stable operation during the starting, $i_{\text {qref }}{ }^{*}$ and the ramp slope must be defined appropriately to avoid $\theta^{*}<0$. The current reference signal is determined from an equilibrium point of (23) at the transition instant under load operation. The equation can be written as

$$
i_{\text {qref }}{ }^{*}=\frac{2\left(\omega_{f} B+T_{l \max }\right)}{P \lambda_{p m} \cos \left(\theta_{t}^{*}\right)}
$$

where $T_{l \max }$ is the maximum load torque during the motor starting and $\theta_{t}{ }^{*}$ is a desired angular difference between an arbitrary and the rotor reference frame at the transition instant.

Assuming that the rotor speed tracks the reference signal in (24),

$$
\omega_{r}=\frac{\omega_{f}}{T_{r}} t .
$$

Then, substituting (26) into (23) and considering $i_{q}{ }^{*}=i_{\text {qref }}{ }^{*}$ and $t=T_{r}$, the time period $T_{r}$ can be determined by:

$$
T_{r}=\frac{\omega_{f} J}{\frac{P}{2} \lambda_{p m} i_{q r e f}{ }^{*} \cos \left(\theta_{r p}{ }^{*}\right)-T_{l \max }-B \omega_{f}}
$$

where $\theta_{r p}{ }^{*}$ is a desired angular difference between an arbitrary and the rotor reference frame at the end of the ramp.

It can be concluded from (25) and (27) that if $\theta_{t}{ }^{*}$ is approximately equal to $\theta_{r p}{ }^{*}, T_{r}$ will tend to infinity. As a result, $\theta_{t}{ }^{*}$ must be larger than $\theta_{r p}{ }^{*}$ to ensure a suitable motor starting interval. In addition, the ramp slope can be increased by enlarging the difference between $\theta_{r p}{ }^{*}$ and $\theta_{t}{ }^{*}$. The parameters required to obtain $T_{r}$ and $i_{q r e f}{ }^{*}$ are usually available for a given motor (e.g. pole number, inertia moment, maximum load, PM flux) or can be determined by tests (e.g. friction coefficient).

\section{Transition Strategy}

During I- $f$ control, the currents and voltages are also referred in the rotor reference frame, as shown in Figure 3. This procedure allows to recalculate the current controllers avoiding undesired transients.

The transition strategy is performed in two steps: $d-q$ current references are redefined and the current controller states are replaced by values that are expressed in the rotor reference frame.

The reference currents are redefined to keep the electromagnetic torque approximately constant. For this 
purpose, it is taken into consideration (22) to define:

$$
\begin{aligned}
& i_{\text {dref }}=0 \\
& i_{\text {qref }}=i_{q(k-1)}=i_{q}{ }^{*}(k-1) \cos \left(\theta_{(k-1)}^{*}\right) .
\end{aligned}
$$

The feedforward actions for decoupling the current control loops, $v_{f d}$ and $v_{f q}$ of Figure 3, are obtained by:

$$
\begin{aligned}
& v_{f d(k-1)}=-\hat{\omega}_{r(k-1)} L_{q} i_{q(k-1)} \\
& v_{f q(k-1)}=\hat{\omega}_{r(k-1)}\left(L_{d} i_{d(k-1)}+\lambda_{p m}\right) .
\end{aligned}
$$

The above variables are only adopted after the transition. Before this event, they are kept at zero.

Now, considering the $d-q$ currents and voltages in the rotor reference frame, (30) and (31), the states of the current controllers for the transition are determined by:

$$
\begin{aligned}
& u_{c d(k-1)}=v_{d(k-1)}+\hat{\omega}_{r(k-1)} L_{q} i_{q(k-1)} \\
& u_{c q(k-1)}=v_{q(k-1)}-\hat{\omega}_{r(k-1)}\left(L_{d} i_{d(k-1)}+\lambda_{p m}\right) \\
& e_{c d(k-1)}=-i_{d(k-1)} \\
& e_{c q(k-1)}=0 .
\end{aligned}
$$

The use of low pass filters $\left(\mathrm{LPF}_{4}\right)$ can be useful to improve the transition by filtering out the high frequency oscillation components of (32)-(34). In addition, speed oscillations during the ramp-up can be attenuated by decreasing the bandwidth of the current control loop. When the disturbance rejection capability is reduced, $\theta^{*}$ is damped causing an attenuation in the electromagnetic torque oscillations. In this paper, $K_{C 1}$ is increased after the transition to enlarge the bandwidth of the control loop.

Finally, the rotor speed is controlled in closed loop after the direct current converges to zero. Here, the reference speed is equal to the desired speed of the starting method.

\section{SIMULATION AND EXPERIMENTAL RESULTS}

The proposed method has been simulated in PSIM using the parameters given in Table I, and the filter cutoff frequencies and gain crossover frequencies given in Table II. No-load and full load conditions at transition instant are adopted to verify the robustness of the method.

Figure 5 presents the experimental platform. It consists of a fixed-point DSP interface (TMS320F2812), an integrated power module developed and optimized for electronic motor control in appliance applications (three phase PWM inverter), an auxiliary PC, an absolute encoder, a BLDC motor, and a BLDC generator. The auxiliary $\mathrm{PC}$ is used for programming the DSP and recording the internal variables from DSP memory. The load torque is synthesized by the generator that is connected to a resistive load. As a result, the load torque is proportional to rotor speed as previously mentioned in section II. The load torque equation is given in Table I.

The stages of operation are detailed in Figures 6 and 7. Here, the rotor is aligned in the first second. In the following, the motor is accelerated up to $1000 \mathrm{rpm}$, and the transition between the open-loop control and the sensorless FOC is performed at $5 \mathrm{~s}$. In addition, the stator voltages are shown in rotor reference frame, whereas the stator currents are

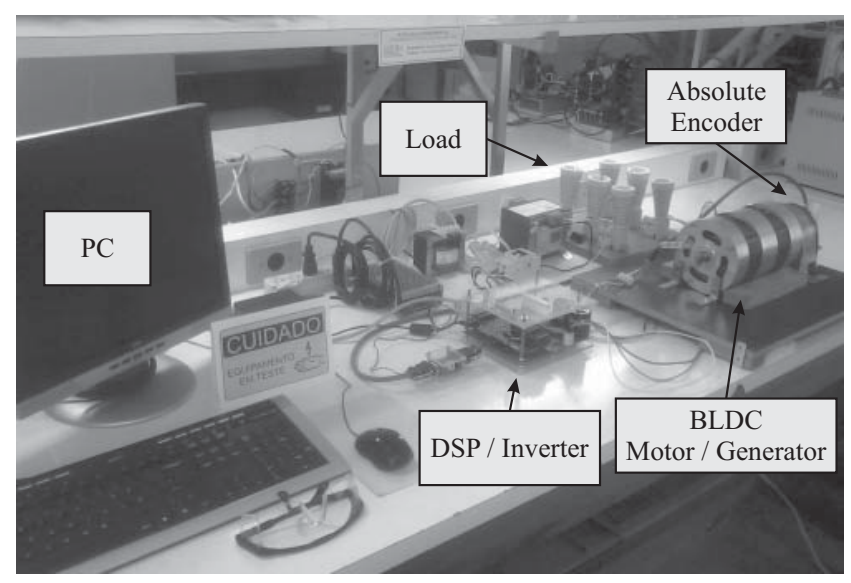

Fig. 5. Experimental platform.

presented in stationary, arbitrary and rotor reference frames. It is seen in these figures that during the I- $f$ starting interval, the $d^{*}-q^{*}$ currents converge to their references that are given in Table I. In addition, it can be seen that the oscillations are damped, which in turn is attributed to the proper selection of the gain crossover frequencies. Note that the estimated rotor speed follows the actual speed demonstrating the effectiveness of the observer. Moreover, the electromagnetic torque is kept approximately constant during the transition revealing the excellent performance of the proposed method.

Figure 8 shows the estimation errors of the electrical rotor position under no-load and full load operation. The average absolute error is around $-1.1^{\circ}$ (electrical degrees)

TABLE I

Simulation/ Platform Parameters

\begin{tabular}{cccc}
\hline Symbol & Value & Symbol & Value \\
\hline$R_{s}$ & $3.4 \Omega$ & $\lambda_{p m}$ & $0.214 \mathrm{~Wb}$ \\
\hline$V_{D C}$ & $300 \mathrm{~V}$ & $J$ & $0.82 \mathrm{mKg} \cdot \mathrm{m}^{2}$ \\
\hline$L_{s}$ & $55 \mathrm{mH}$ & Poles & 4 \\
\hline$T_{s}$ & $0.1 \mathrm{~ms}$ & $B$ & $0.373 \mathrm{mN} \cdot \mathrm{m} . \mathrm{s}$ \\
\hline Power & $100 \mathrm{~W}$ & $T_{l}$ & $\left(0.0022 \omega_{r}\right) \mathrm{N} . \mathrm{m}$ \\
\hline$\omega_{r \max }$ & $4000 \mathrm{rpm}$ & $\omega_{f}$ & $1000 \mathrm{rpm}$ \\
\hline$K_{\text {obs }}$ & 680 & $K_{\text {com }}$ & 0.0003587 \\
\hline$K_{C 1}$ & $20 \mid 50$ & $K_{C 2}$ & 0.9877 \\
\hline$K_{\omega 1}$ & 0.01 & $K_{\omega 2}$ & 0.9999 \\
\hline$\theta_{t}^{*}$ & $38^{\circ}$ & $\theta_{r p}^{*}$ & $5^{\circ}$ \\
\hline$i_{q r e f}{ }^{*}$ & $0.8 \mathrm{~A}$ & $i_{d r e f}{ }^{*}$ & $0 \mathrm{~A}$ \\
\hline$T_{r}$ & $1.25 \mathrm{~s}$ & $T_{l m a x}$ & $0.23 \mathrm{~N} . \mathrm{m}$ \\
\hline
\end{tabular}

TABLE II

Filter Cutoff and Gain Crossover Frequencies

\begin{tabular}{cc}
\hline Structure & Frequency (Hz) \\
\hline $\mathrm{SLPF}_{1}$ & $1 \mathrm{k}$ \\
\hline $\mathrm{SLPF}_{2}$ & 250 \\
\hline $\mathrm{SLPF}_{3}$ & 25 \\
\hline $\mathrm{LPF}_{4}$ & 0.5 \\
\hline $\mathrm{HPF}$ & $3 \mathrm{k}$ \\
\hline Open-loop transfer function (current loop) & $55 \mid 145$ \\
\hline Open-loop transfer function (speed loop) & 2 \\
\hline Observer & $\approx 2 \mathrm{k}$ \\
\hline
\end{tabular}




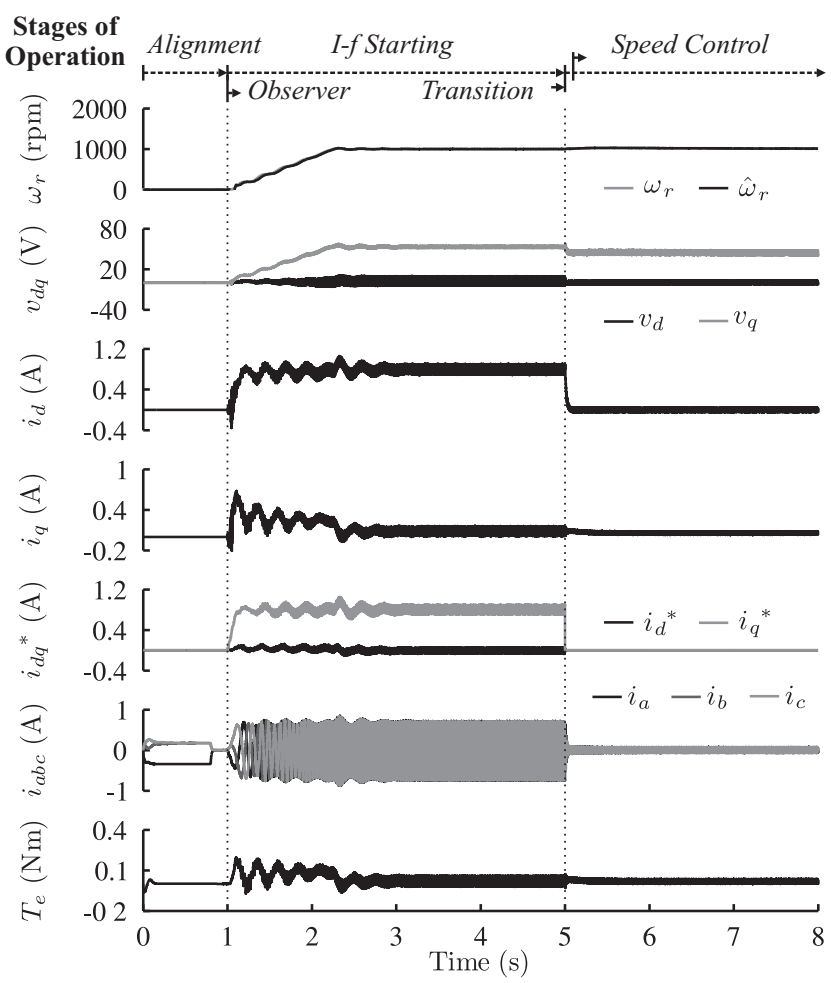

Fig. 6. Simulation result: Motor starting under no-load operation.

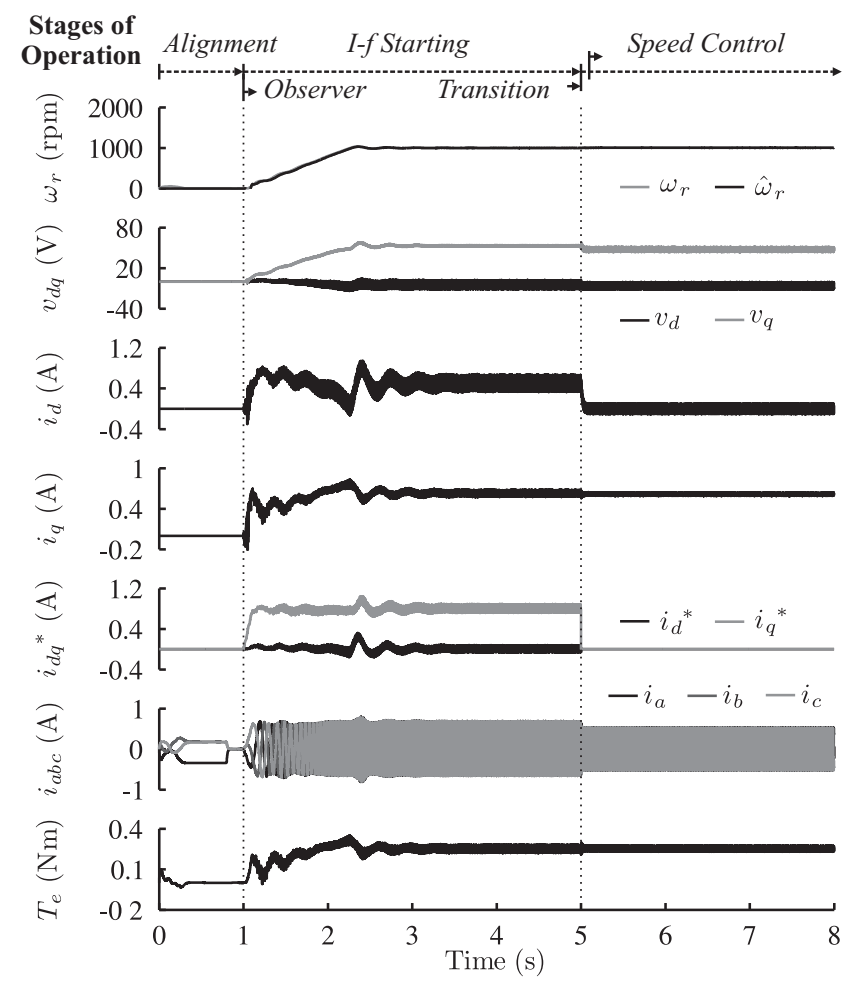

Fig. 7. Simulation result: Motor starting under full load operation.

after the transition. The previously mentioned convergence assumption is confirmed as well as the effectiveness of the proposed phase lag compensation. High frequency components that can be seen in the errors are attributed to the nonsinusoidal back-EMF.
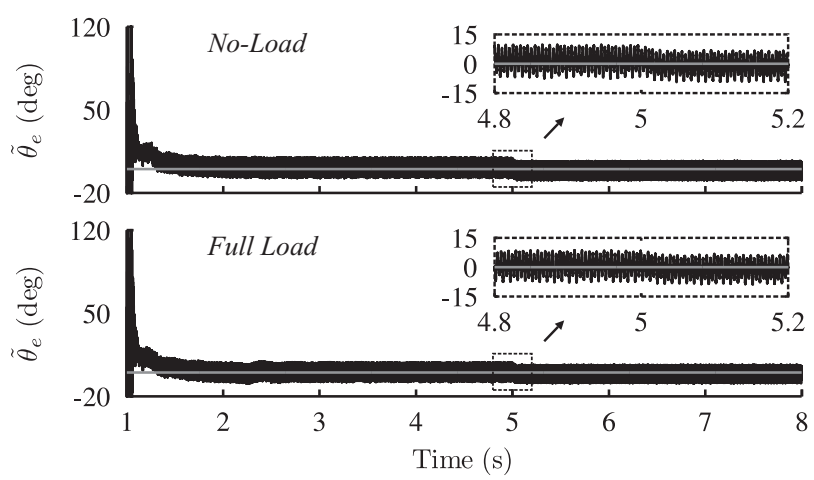

Fig. 8. Simulation result: Estimation error of the electrical rotor position under no-load and full load operation.

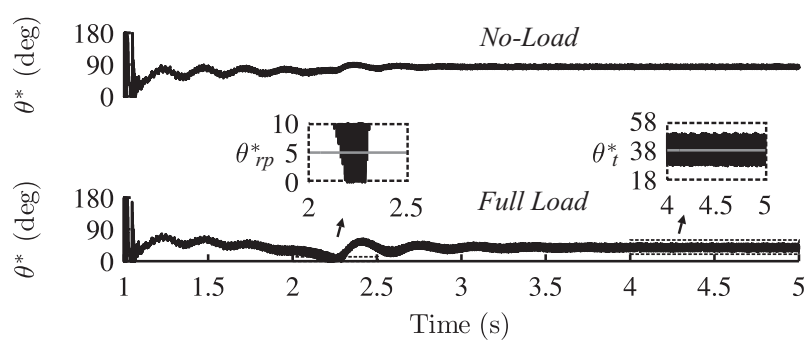

Fig. 9. Simulation result: Angular difference between the arbitrary and rotor reference frame during the proposed starting method under no-load and full load operation.

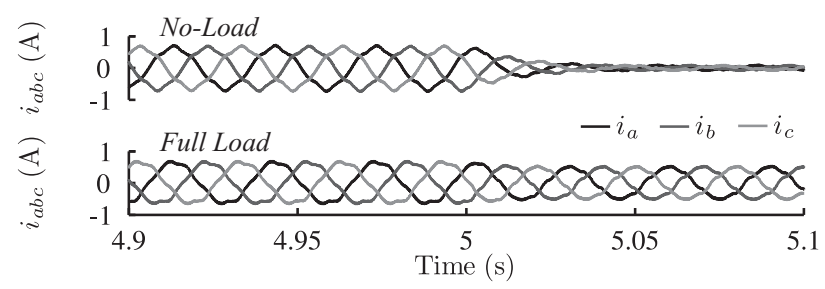

Fig. 10. Simulation result: Stator phase currents during the transition under no-load and full load operation.

Although damped oscillation can be observed in Figure 9, the average angular difference converges to the designed values of $\theta_{r p}{ }^{*}$ and $\theta_{t}{ }^{*}$. As a result, this congruence indicates that starting method design is a suitable procedure.

Figure 10 shows the stator currents and reveals the smooth transient during the transition even with a d-axis reference current step for correcting the field orientation.

The experimental tests were performed in the platform shown in Figure 5 using the parameters given in Table I and II. In order to present the experimental results, internal variables of DSP that were recorded by the auxiliary PC are used to draw Figures 11 to 14, whereas sampled points of a oscilloscope are used to draw Figure 15.

In general, a good agreement is found between the experimental results of Figures 11 to 15 and the simulations results. Thus, it can be concluded from the results that the proposed I- $f$ starting method provides a good dynamic performance and robustness to different load conditions.

The results that are shown in Figures 11 and 12 are consistent with simulations and they confirm the good performance and effectiveness of the implemented starting 


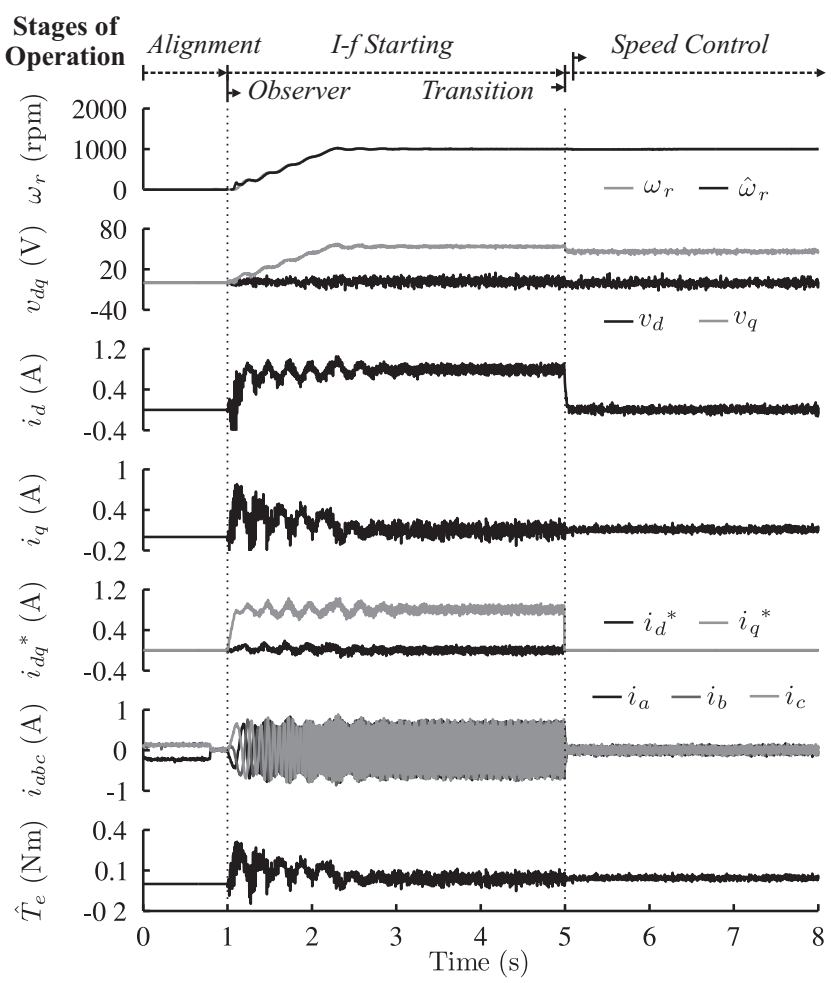

Fig. 11. Experimental result: Motor starting under no-load operation.

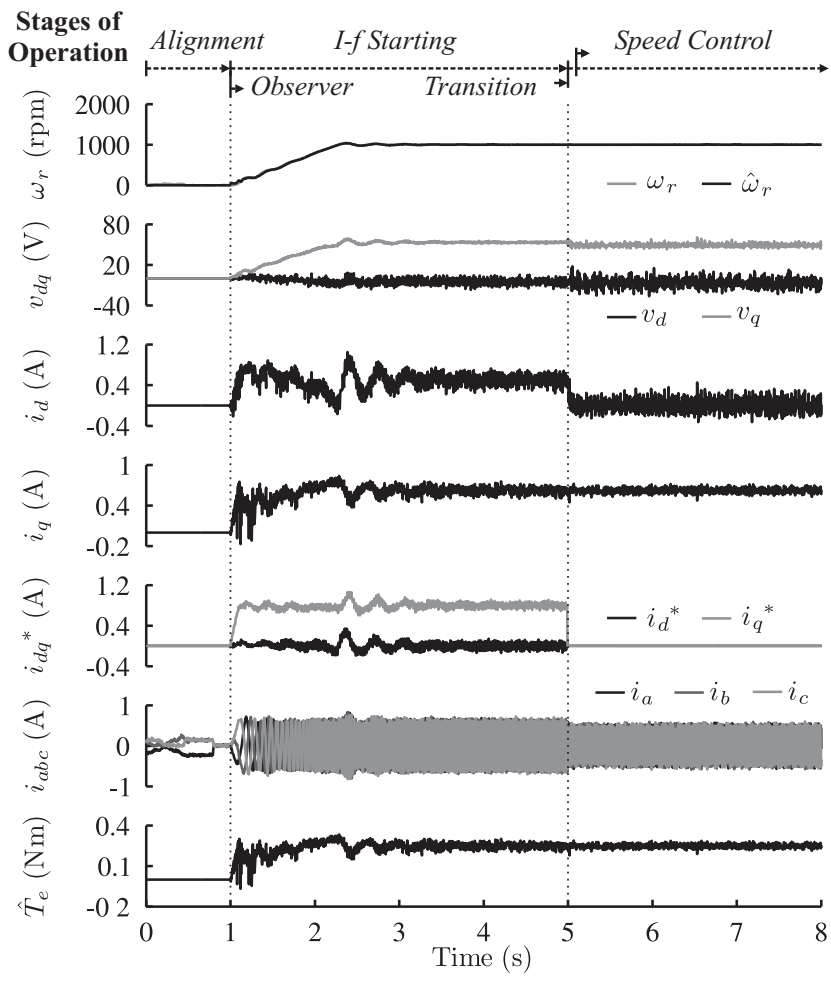

Fig. 12. Experimental result: Motor starting under full load operation.

method. In addition, the magnitude and the oscillations of the stator voltages, currents and electromagnetic torque are very similar to the previous results. Here, the estimated electromagnetic torque was determined using (4).
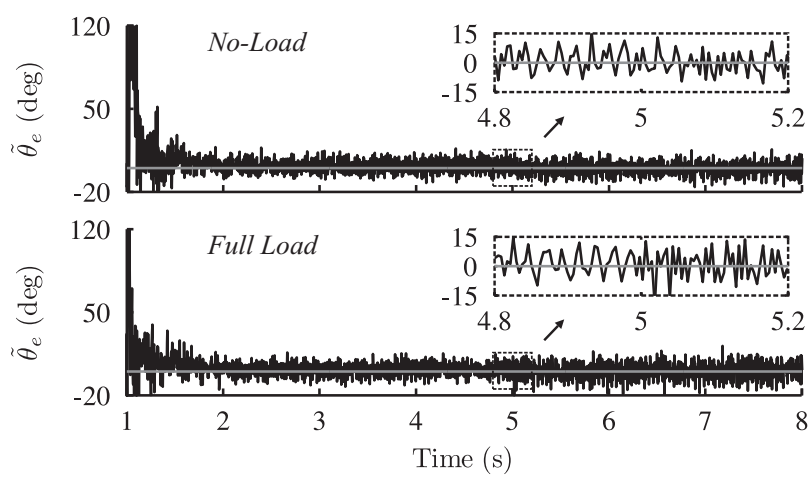

Fig. 13. Experimental result: Estimation error of the electrical rotor position under no-load and full load operation.

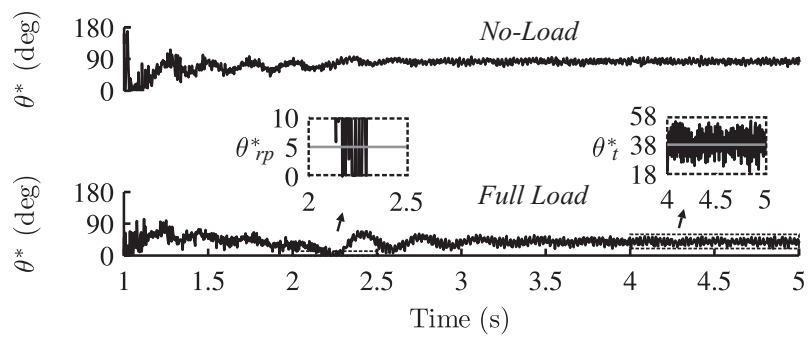

Fig. 14. Experimental result: Angular difference between the arbitrary and rotor reference frame during the proposed starting method under no-load and full load operation.

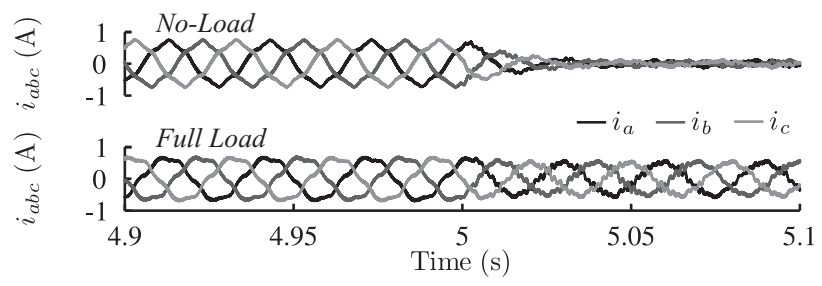

Fig. 15. Experimental result: Stator phase currents during the transition under no-load and full load operation.

Figure 13 presents the orientation error of the rotor reference frame with the average absolute error around $-0.4^{\circ}$ (electrical degrees). This error was computed by using the difference between the estimated rotor position and the measured angle from an absolute encoder.

Similar to the simulation results, the average angular difference between reference frames converges to the designed values, $5^{\circ}$ at the end of ramp-up and $38^{\circ}$ at the transition, as indicated in Figure 14. Thus, these results validate the starting design procedure again.

A smooth and fast transition is confirmed by Figure 15 which presents the stator phase currents at the transition instant.

\section{CONCLUSION}

This paper proposes an I- $f$ starting method for smooth and fast transition from open-loop frequency control to sensorless FOC of BLDC motors. The proposed method keeps the electromagnetic torque approximately constant during the transition stage avoiding undesired current and speed transients. In addition, it is shown that the design 
procedure for the speed reference signal ensures a suitable motor starting. Moreover, this method allows to reduce the complexity of the starting motor design and to minimize the time interval of the transition stage when it is compared with the previously reported methods. Furthermore, the methodology can be easily adapted for other controllers (e.g. sliding mode controllers). Although, the alignment stage may be considered a drawback in some applications due to a possible reversal rotation, high-frequency signal methods can be used to estimate the initial rotor position. Finally, the good performance and robustness of the method has been demonstrated by both simulation and experimental results.

\section{ACKNOWLEDGEMENT}

The authors would like to express their gratitude to Coordination of Improvement of Higher Education Personnel (CAPES) and National Council for Scientific and Technological Development (CNPq).

\section{REFERENCES}

[1] A. Rahman, "History of interior permanent magnet motors", IEEE Industry Applications Magazine, vol. 19, pp. 10-15, January/February 2013.

[2] R. Krishnan, Permanent Magnet Synchronous and Brushless DC Motor Drives, CRC Press, United States of America, 2009.

[3] P. P. Acarnley, J. F. Watson, "Review of positionsensorless operation of brushless permanent-magnet machines", IEEE Transactions on Industrial Electronics, vol. 53, pp. 352-362, April 2006.

[4] O. Benjak, D. Gerling, "Review of position estimation methods for ipmsm drives without a position sensor part $\mathrm{i}$ - nonadaptive methods", in Proc. of ICEM, pp. 1-6, 2010.

[5] O. Benjak, D. Gerling, "Review of position estimation methods for ipmsm drives without a position sensor part ii - adaptive methods", in Proc. of ICEM, pp. 1-6, 2010.

[6] O. Benjak, D. Gerling, "Review of position estimation methods for pmsm drives without a position sensor, part iii - methods based on saliency and signal injection", in Proc. of ICEMS, pp. 873-878, 2010.

[7] Z. Wang, K. Lu, F. Blaabjerg, "A simple startup strategy based on current regulation for back-emf-based sensorless control of pmsm", IEEE Transactions on Power Electronics, vol. 27, pp. 3817-3825, August 2012.

[8] R. Wu, G. R. Slemon, "A permanent magnet motor drive without a shaft sensor", IEEE Transactions on Industry Applications, vol. 27, pp. 1005-1011, September/ October 1991.

[9] S. Ogasawara, H. Akagi, "An approach to position sensorless drive for brushless dc motors", IEEE Transactions on Industry Applications, vol. 27, pp. 928933, September/October 1991.

[10] J. Qi, Y. Tian,Y. Gong, C. Zhu, X. Zhao, "A new start method for rolling piston compressor based on dsp to improve the load performance", in Proc. of ICAL, pp. 543-548, 2009.
[11] K.-W. Lee, D.-K. Kim, B.-T. Kim, B.-I. Kwon, "A novel starting method of the surface permanent-magnet bldc motors without position sensor for reciprocating compressor", IEEE Transactions on Industry Applications, vol. 44, pp. 85-92, January/February 2008.

[12] C. L. Baratieri, H. Pinheiro, "A novel starting method for sensorless brushless dc motors with current limitation", in Proc. of ICEM, pp. 816-822, 2012.

[13] G. H. Jang, J. H. Park, J. H. Chang, "Position detection and start-up algorithm of a rotor in a sensorless bldc motor utilising inductance variation", IEE Proc.-Electric Power Applications, vol. 149, pp. 137-142, March 2002.

[14] F. Briz, M. W. Degner, "Rotor position estimation", IEEE Industrial Electronics Magazine, vol. 5, pp. 24-36, June 2011.

[15] M. Fatu, R. Teodorescu, I. Boldea, G. Andreescu, F. Blaabjerg, "I-f starting method with smooth transition to emf based motion-sensorless vector control of pm synchronous motor-generator", in Proc. of PESC, pp. 1481-1487, 2008.

[16] A. Stirban, I. Boldea, G.-D. Andreescu, "Motionsensorless control of bldc-pm motor with offline feminformation-assisted position and speed observer", IEEE Transactions on Industry Applications, vol. 48, pp. 19501958, November/December 2012.

\section{BIOGRAPHIES}

Cassio Luciano Baratieri was born in Erechim, Rio Grande do Sul, Brazil, in 1984. He received the B.S. and M.S. degrees in electrical engineering from the Federal University of Santa Maria, Santa Maria, Brazil, in 2009 and 2011, respectively.

Since 2007, he has been a member of the Power Electronics and Control Research Group, Santa Maria, Brazil. Currently, he is a doctoral student of the Graduate Program in Electrical Engineering at the Federal University of Santa Maria. His current research interests include control of electrical machines.

M.S. Baratieri is a student member of SOBRAEP and a graduate student member of the IEEE Industry Applications and IEEE Industrial Electronics Societies.

Humberto Pinheiro was born in Santa Maria, Rio Grande do Sul, Brazil, in 1960. He received the B.S. degree from the Federal University of Santa Maria (UFSM), Santa Maria, in 1983, the M.Eng. degree from the Federal University of Santa Catarina, Florianópolis, Brazil, in 1987, and the Ph.D. degree from Concordia University, Montreal, QC, Canada, in 1999.

From 1987 to 1990, he was a Research Engineer with a Brazilian UPS company and then joined the Pontifícia Universidade Católica do Rio Grande do Sul, Porto Alegre, Brazil, where he lectured on power electronics. Since 1991, he has been with the UFSM. His current research interests include grid connected three-phase converters, wind energy conversion systems, and control applied to power electronics systems.

Dr. Pinheiro is a member of SOBRAEP, IEEE Power Electronics Society and IEEE Industrial Electronics Society. 